\title{
FUTBOLCULARIN ULUSAL TAKIMLARDA OYNAMA SAYILARINA GÖRE LIDERLIKK GÜCÜ ALGILARI
}

\author{
Erkut KONTER ${ }^{1}$
}

Geliş Tarihi: 05.09.2007

Kabul Tarihi: 15.02.2008

\section{ÖZET}

Bu araştırmanın amacı; futbolcuların ulusal takımlarda (genç, ümit ve A ulusal takımları) oynama sayılarına (hiç oynamama, 15 arası oynama ve 6-58 arası oynama) göre liderlik gücü algılarını (Zorlayıcılık Gücü-ZG, Özdeşleşim Gücü-ÖZG, Yasal Güç-YG ve Uzmanlık Gücü-UG) araştırmaktır. Bu araştırmada; Futbolda Liderlik Gücü Ölçeği-Diğer (FLGÖ-D: Futbolcu Formu) ve futbolcuların ulusal takımlarda oynama sayılarıyla ilgili soruları da içeren bir anket formu kullanılmıştır. FLGÖ-D ile erkek futbolculardan ( $n=870$ ) toplanan verilerin Tek Yönlü Anova analizleri; futbolcuların ulusal takımlarda oynama sayıları ile hiçbir liderlik gücü algısında anlamıı bir farklıık ortaya koymamışıı ( $p>0.05$ ). Ancak, futbolcuların ulusal takımlarda oynama sayıları ile ÖZG algısı arasında anlamlı farklıı̆̆a çok yakın olan bir değer bulunmuştur $[F(867)=2.83, p<0.06]$. Tukey Testi, $1-5$ arasında ulusal takımda oynayan futbolcuların ( $\bar{X}=21.34), 6-58$ arasında oynayan futbolculara göre $(\bar{X}=19.41)$ antrenörlerinin ÖZG'nü daha yüksek algıladıklarını ortaya koymuştur. Genel olarak ÖZG ortalamalarına bakıldığında, ulusal takımlarda hiç oynamamadan $(\bar{X}=18.17)$ az sayıda oynamaya doğru (1-5 arası) ÖZG algısı artmakta ( $\bar{X}=21.34$ ), ulusal takımlarda daha çok sayıda oynamaya doğru ilerlendiğinde ise (6-58) ÖZG algısı biraz aşağıya düşmektedir $(\bar{X}=19.41)$. Daha kesin sonuçlar çıkarabilmek için, daha ayrıntıı ulusal takımlarda oynama sıklıkları ve çeşitli ulusal takımlarda oynama düzeyleri de dikkate alınarak yapılacak araştırmalara gereksinim vardır.

Anahtar Kelimeler: Liderlik Gücü Algısı, Futbolcu, Futbol, Oynama Sayısı, Ulusal Takımlar.

\section{LEADERSHIP POWER PERCEPTION OF SOCCER PLAYERS ACCORDING TO FREQUENCY OF PLAYING FOR THE NATIONAL TEAMS}

\begin{abstract}
ABSRACT
The purpose of this study was to analyze the leadership power perception of soccer players according to frequency of playing for the national teams Adapted Turkish version of Power in Soccer Questionnaire-Other (PSQ-O for soccer players) and a questionnaire related to demographic variables were used in this study. Data were collected from male soccer players $(n=870)$. One-Way Anova Analysis of PSQ-O revealed no significant differences between the soccer players' playing frequency for the national teams and their any leadership power perception (Coercive Power, Referent Power, Legitimate Power and Expert Power, p>.05). However, analysis of data indicated a very close result to the meaningful difference related to Referent Power $[F(867)=2.83, p<.06]$. Tukey Test showed that; soccer players making national teams between 1-5 $(\bar{X}=21.34)$ have higher perception of Referent Power than soccer players making national teams 6-58 $(\bar{X}=19.41)$. Over all, national ones have higher mean scores of Referent Power perception than none national ones. Although score of referent power of soccer players increases from none national to be national, than decrease again by the more frequency of being national (curvilinear). Further research is needed with different frequencies and level of playing in order to deeper understanding the results.
\end{abstract}

Key Words: Leadership Power Perception, Soccer Players, Soccer, Frequency of playing, National Teams.

\section{GiRiş}

Sporda başarı ve performansı etkileyen önemli faktörlerden birisi liderliktir. Sporda liderlik, araştırmacıların oldukça ilgisini çeken bir konu olmasına karşın (1), "Sporda Liderlik Gücü“ ile ilgili araştırmalar oldukça azdır (2).

"Sosyal Güç" (social power) veya "Kişilerarası Güç" (interpersonal power); bir kişinin (örneğin antrenörün), diğerlerinin (örneğin sporcuların) tutumlarını ve davranışları etkileyebilme ve değiştirebilme becerisidir $(2,3)$. French ve Raven (3), kişilerarası ilişkiler açısından beş güç faktörünü ileri sürmüşlerdir. Bunlar; ödülün gücü (ÖDG), zorlayıcılık

\footnotetext{
1 Dokuz Eylül Üniversitesi Buca Eğitim Fakültesi
} 
gücü (ZG), yasal güç (YG), uzmanlık gücü (UG) ve özdeşleşim gücüdür (ÖZG). "ÖDG”; diğerlerini ödüllendirebilme, "ZG"; bir veya birkaç cezalandırma çeşidini gerektiğinde uygulayabilme, "YG"; kişinin organizasyon, grup veya takımdaki yetkisini, otoritesini ve mevkisini kullanabilme, "UG"; belirli bir özel alanda bilgili ve becerili olabilme, "ÖZG" ise; takip edenler veya grup üyeleri tarafından sevilen ve saygı duyulan biri olabilme olarak tanımlanabilir $(2,3)$.

Chelladurai (4), güçlerle ilişkili olarak; otokrat davranışın ZG ve YG ile demokratik davranışın, antrenman ve bilgi verme ile (UG), sosyal desteğin ÖZG ile, olumlu geri bildirim vermenin ise ÖDG ile benzer olduğunu belirtmiştir. Yukarıda verilen bilgilere paralel olarak; itaat ettirmenin ZG ve ÖDG ile, sosyal destek vermenin ÖZG ile, içselleştirmenin YG ve UG ile, pozisyonun YG, ÖDG ve ZG ile, kişisel gücün ise UG ile ilişkisi kurulabilir $(2,5,6)$. Bunlara ek olarak, konugörev yönelimli olmanın (task orientation) UG ile, ilişki-sporcu yönelimli olmanın ise (relationship orientation) ÖZG ile bağı kurulabilir.

Liderlik gücü algısının doyumu, (7,8), yetenek algısını (9), olumlu değerlendirme yapmayı (10), takım bütünleşmesini (11), imgelemeyi, stresle başa çıkmayı ve karşılaşma kaygısını yönetmeyi (12), performansı ve başarıyı $(13,14,15)$ etkilediği çeşitli araştırmalarda gösterilmiştir.

Leith (16), yaş, eğitim, beceri düzeyi ve liderlikle ilişkili olarak Tablo 1'deki bilgileri vermiştir.

Tablo 1. Sporcuların Farklı Yaş, Beceri ve Eğitim Düzeylerine Göre Liderlik Süreci

\begin{tabular}{|c|c|c|}
\hline Yaş/Beceri ve Eğitim & $\begin{array}{c}\text { Konu-Görev Yönelimli } \\
\text { (UG) }\end{array}$ & $\begin{array}{c}\text { İlişki-Sporcu Yönelimli } \\
\text { (ÖZG) }\end{array}$ \\
\hline Çocuk ve Gençler & Düşük & Çok Yüksek \\
\hline Lise & Orta-Düşük & Orta-Yüksek \\
\hline Üniversite & Orta-Yüksek & Orta-Düşük \\
\hline Profesyonel & Yüksek & Düşük \\
\hline
\end{tabular}

Tablo 1'den de görülebileceği gibi çocuklarda (ilköğretim); düşük UG ve çok yüksek ÖZG daha çok gerekirken lisede, orta-düşük UG ve orta-yüksek ÖZG ve üniversitede ise; orta-yüksek UG ve orta-düşük ÖZG'ne daha çok gereksinim duyulmaktadır. Profesyonellerde ise yüksek UG ve düşük ÖZG algısı olduğu ileri sürülmektedir.

Chelladurai ve Carron (17) olgunluk düzeyini; yaş, deneyim ve yarışma düzeyi olarak işlevselleştirmişler ve sporda az olgunlaşmış olanların, yüksek ilişki yönelimli (ÖZG) ve daha olgun olanların ise ÖZG'ne daha az gereksinim duyduklarını belirtmişlerdir. Araştırma sonuçlarına göre; konu yönelimli liderlik davranışının önemi (örneğin antrenman ve bilgilendirme, olumlu geri bildirim-UG) düşük olgunluk düzeyinden orta olgunluk düzeyine gelindiğinde artmakta, yüksek olgunluk düzeyine gelindiğinde ise tekrar aşağıya düşmektedir (ters $U$ hipotezi).

Erle (18), branşlarında daha deneyimli olan sporcuların, olumlu geri bildirimi (UG) daha çok tercih ettiklerini belirtmesine karşın, Chelladurai ve Carron'ın (19) araştırma sonuçları, daha deneyimli olanların daha çok otokratik davranış (YG) ve sosyal destek (ÖZG) aradıklarını ortaya koymuştur. Terry (20), elit sporcuların, kulüp sporcularına göre, daha çok demokratik ve sosyal destek (ÖZG) ve daha az olumlu geri bildirim davranışı (UG) tercih ettiklerini belirtmiştir. Riemer ve Toon (21), daha yetenekli olan sporcuların (en üst liglerde oynayanlar) daha az yetenekli olanlara göre, daha az olumlu geri bildirim (UG) davranışına gereksinim duyduklarını bulmuşlardır.

Chelladurai ve Carron (22), yaptıkları araştırmada sportif olgunluk düzeyini olarak;

a) Yarışmasal düzeyde sporları (lise 1, lise 2, lise 3 ve üniversiteler arası basketbol),

b) Basketbol oynama deneyimlerini ve

c) Sporcuların yaşlarını dikkate alarak, her üç durumda da benzer sonuçları elde etmişlerdir.

Araştırmada; ilk olarak, sosyal destekte (ilişki yönelimli olma-ÖZG) doğrusal bir ilişki bulunmuştur. Bir başka deyişle, olgunluk, yaş ve deneyimin artışıyla ilişki yönelimli olma veya sosyal destek arama davranışı artmıştır (ÖZG). İkinci olarak, antrenman ve bilgilendirme (konu yönelimli davranış-UG) lise 1'den (14-15 yaş) lise 3'e (yaş 18-19) doğru düşerken üniversite sporlarında (yaş 18-24) tekrar artma göstermiştir.

Garland ve Barry (13), performansı, oynama süresi olarak tanımlayarak (örneğin aslar, yedekler ve genel takım kadrosunda yer alanlar); antrenman ve bilgilendirme, demokratik davranış, otokratik davranış, olumlu geri bildirim verme ve sosyal destek sağlamadan meydana gelen beş liderlik faktörünün, performansı tahmin etmede önemli olduğunu göstermişlerdir. Performans düzeyini en güçlü tahmin eden faktörün ise otokratik davranış olduğu (YG), otokratik davranış ile daha düşük performans arasında anlamlı bir farklılık olduğu bulunmuştur. Bu sonucu destekleyici olarak, Robinson ve Carron (23), daha az başarılı olan sporcuların, antrenörlerini daha otokratik olarak değerlendirdiklerini göstermişlerdir. Kazanma ve kaybetme kayıtlarını dikkate alarak performansı değerlendiren araştırmalar (örneğin; 14); başarılı olan takımlardaki sporcuların, başarılı olmayan takımlardakilere göre, daha çok antrenman ve bilgilendirme (UG), demokratik davranış, olumlu geri bildirim (UG) ve sosyal destek (ÖZG) algılamalarını ortaya koymuştur. Buna karşıt olarak; Serpa ve arkadaşları (24), hentbol 1988 dünya şampiyonasında birinci takımda yer alanların sonuncu takımda yer alanlara göre, daha yüksek otokratik davranış (YG), daha az olumlu geri bildirim (UG), sosyal destek (ÖZG) ve demokratik davranış (UG) algıladıklarını belirlemişlerdir. 
Konter (25), futbol antrenörlerinin ve futbolcuların profesyonel ve amatör olmalarına göre liderlik gücü algıları ile ilgili araştırmasında; profesyonel ve amatör futbolcular arasında ÖZG ve YG algıları açısından anlamlı bir farklılık olduğunu belirtirken, ZG ve UG algıları açısından anlamlı bir farklılık olmadığını belirtmiştir. Ancak, ZG ve UG algılarının sonuçları da anlamlı farklılığa çok yakın bulunmuştur (ZG; $p<0.06$ ve UG; $p<0.07$ ). Araştırma sonuçları; profesyonel futbolcuların, amatör futbolculara göre, daha yüksek ÖZG ve YG ve daha düşük ZG ve UG algıladıklarını ortaya koymaktadır.

Konter ve Doğanay (26), futbolcuların amatör ve profesyonel olmalarına göre, 'Baskı Altında Doruk Performans Ortaya Koyma Becerisinin' anlamlı bir farklılık gösterdiklerini belirtmişlerdir $(p<0.05)$. Amatör futbolcuların 'Baskı Altında Doruk Performans Ortaya Koyma Becerisi' profesyonellere göre daha yüksek saptanmıştır. Bu sonuç, futbol profesyonel düzeyde oynandığında baskıyla başa çıkma faktörünün daha da önemli hale geldiğini ve futbolcuların daha da güçlük yaşayabileceğini göstermiştir. Konter (27), "Profesyonel Futbolcuların Ulusal Takımlarda Oynama Düzeylerine Göre' psikolojik becerilerini (imgeleme, baskı altında doruk performans, bağlılık gösterme, stresle başa çıkma ve karşılaşma kaygısını yönetme) araştırmıştır. Araştırma sonuçları, profesyonel futbolcuların ulusal takımlarda oynama düzeyleri ile psikolojik becerileri arasında anlamlı bir farklıığı göstermemesine karşın, ulusal takımlarda oynama düzeyi ile 'Baskı Altında Doruk Performans Ortaya Koyma Becerisi' arasında anlamlı bir farka çok yakın olan bir değer bulunmuştur [F; (2) 2.53, p <0.08]. Analiz sonuçları; ulusal takımlarda yer alanların almayanlara göre, daha iyi 'Baskı Altında Doruk Performans Ortaya Koyma Becerisi' gösterdiklerini ortaya koymuştur. Konter (27), ayrıca "profesyonel futbolcuların oynadıkları liglere (1, 2 ve 3. lig) göre de psikolojik becerilerini araştırdığı çalışmasında; profesyonel futbolcuların oynadıkları liglerle 'Stresle Başa Çıkma' ve 'Karşılaşma Kaygısını Yönetme' becerilerinin anlamlı farklılıklar ortaya koymamasına karşın, profesyonel futbolcuların oynadıkları liglerle 'İmgeleme', 'Baskı Altında Doruk Performans Ortaya Koyma' ve 'Bağlııı Gösterme' (ÖZG) becerileri arasında anlamlı farklılıklar göstermiştir. Analizlerden elde edilen sonuçlar; 'İmgeleme', 'Baskı Altında Doruk Performans Ortaya Koyma' ve 'Bağlılık Gösterme' becerileri iyi düzeyde olan profesyonel futbolcuların, zayıf düzeyde olanlara göre, daha üst liglerde oynadıklarını göstermektedir.

Futbolcuların ulusal takımlarda oynama sayılarına göre liderlik gücü algılarının araştırılması, futbolda ulusal takıma yükselmede ve oynamayı sürdürmede liderlik gücü algısının oynadığı rolün daha iyi anlaşıımasına, ulusal takımlarda oynama sayılarının başarı ve performansla ilişkisinin aydınlatılmasına yardımcı olabilir. Futbolda liderlikle ilgili birçok araştırma bulunmasına karşın, futbolda liderlik gücü algısı ve ulusal takımlarda oynama sayılarına ilişkin araştırmalar çok azdır. Bu nedenle, bu araştırmanın amacı; futbolcuların ulusal takımlarda oynama sayılarına göre liderlik gücü algılarının incelenmesidir.

\section{MATERYAL VE YÖNTEM}

\section{Araştırma Grubu}

Araştırmaya yaş ortalaması $18.40(S=4.00)$ ve futbol deneyim yılı ortalaması $6.00(S D=4.15)$ olan 870 erkek futbolcu katılmıştır.

\section{Veri Toplama Araçları}

Wann ve arkadaşları (2), French ve Raven'nın (3), kişilerarası güç yaklaşımının sporlara aktarımasına öncülük ederek Sporda Liderlik Gücü-Diğer (SLGÖ-D sporcular formu) ve Sporda Liderlik Gücü-Kendi (SLGÖ-K antrenörler formu) ölçeklerini geliştirmişlerdir. Konter (25), bu ölçeklerin genel olarak sporlar ve özel olarak futbolla ilgili Türkçe'ye uyarlama çalışmasını yapmıştır (sporlar için; SLGÖ-D ve SLGÖ-K, futbol için, FLGÖ-D ve FLGÖ-K). Doğrulayıcı ve açıklayıcı faktör analizleriyle Türkçe'ye uyarlanan FLGÖ-D, 4 faktör ve 10 maddeden meydana gelmektedir. FLGÖ-D'nin alt faktörlerinin güvenirlilik katsayıları ve içsel tutarlılıkları .60 ile .75 arasında değişmektedir (ZG=0.68; ÖZG=0.60; $Y G=0.60$; $U G=0.70$ ). $Z G$ ve $Y G$ faktörlerinde 2'şer madde, ÖZG ve UG faktörlerinde ise 3'er madde bulunmaktadır. FLGÖ-D'nin belirtilen güvenirlilik katsayıları ve içsel tutarlılıkları kabul edilir ölçülerdedir (28). Doğrulayıcı ve açıklayıcı faktör analizleriyle Türkçe'ye uyarlanan FLGÖ-K ise, 4 faktör ve 11 maddeden meydana gelmektedir. FLGÖ-K'nin alt faktörlerinin güvenirlilik katsayıları ve içsel tutarlılıkları .65 ile .84 arasında değişmektedir (ZG=0.66; ÖZG=0.65; $Y G=0.69$; UG=0.84). Sadece YG 2 madde ve diğer alt faktörler ise 3'er maddeden meydana gelmektedir. FLGÖ-K'nin belirtilen güvenirlilik katsayıları ve içsel tutarlılıkları da kabul edilir ölçülerdedir (28). Yukarıda belirtilen her bir ölçek 1 ile (tamamen yanlış-hiç katılmıyorum), 9 arasında değişen Likert tipi bir ölçektir (tamamen doğru-kesinlikle katılıyorum). Örneğin; FLGÖ-K'in (futbol antrenör formu) UG faktöründe yer alan bir madde; "Bu spor konusunda oldukça bilgili olduğum için istediklerimi yapar ve kararlarıma uyarlar." şeklinde ifade edilmektedir.

\section{İşlem ve Verilerin Analizi}

Her bir futbol takımının antrenörüyle anlaşmaya varılarak anket ve ölçekleri uygulama yeri, günü ve saati belirlenmiştir. Anket ve ölçekler uygulanmadan önce, araştırmanın futboldaki etkililik ve algılamayla ilişkili olduğu, kişiye özel bir çalışma olmadığı, bilimsel bir araştırma olduğu, anket ve ölçeklere isim yazılmaması gerektiği, samimi yanıt vermenin sağılılı sonuçlar alınması açısından çok önemli olduğu ve gizlilikle ilgili kurallar açıklanmıştır. Daha sonra 
antrenör ve futbolculara gerekli materyaller sağlanarak uygulamaya geçilmiştir. Her bir formun tamamlanması 10-15 dakika kadar sürmüş ve soru sorulmasına izin verilmiştir. FLGÖ-D ile toplanan verilerin analizinde Tek Yönlü Anova kullanılmıştır.

\section{BULGULAR}

Tablo 2. Futbolcuların Ulusal Takımlarda Oynama Sayılarına Göre Liderlik Gücü Algılarının Tek Yönlü ANOVA Sonuçları

\begin{tabular}{|c|c|c|c|c|c|c|c|c|c|c|c|c|}
\hline \multicolumn{2}{|c|}{$\begin{array}{l}\text { Liderlik Gücü ve } \\
\text { Ulusal Takım }\end{array}$} & $\mathrm{n}$ & $\bar{X}$ & s & S.H & $\begin{array}{c}\text { Varyansın } \\
\text { Kaynağı }\end{array}$ & $\begin{array}{l}\text { Kareler } \\
\text { Toplamı }\end{array}$ & Sd & $\begin{array}{c}\text { Kareler } \\
\text { Ortalaması }\end{array}$ & $\mathbf{F}$ & $p$ & $\begin{array}{l}\text { Anlamlı } \\
\text { Fark }\end{array}$ \\
\hline \multirow{4}{*}{ ZG } & Hiç & 808 & 8.71 & 4.89 & .17 & $\begin{array}{c}\text { Gruplar } \\
\text { Arası }\end{array}$ & 44.17 & 2 & \multirow[t]{2}{*}{22.09} & \multirow{4}{*}{.94} & \multirow{4}{*}{.39} & \multirow{4}{*}{ YOK } \\
\hline & $1-5$ & 30 & 7.80 & 4.20 & .77 & Grup İçi & 20478.38 & 867 & & & & \\
\hline & $6-58$ & 32 & 7.87 & 4.60 & .81 & & & & \multirow[t]{2}{*}{23.62} & & & \\
\hline & Toplam & 870 & 8.65 & 4.86 & .16 & Toplam & $\angle 05 \angle 2.56$ & 869 & & & & \\
\hline \multirow{4}{*}{ ÖZG } & Hiç & 808 & 19.38 & 5.48 & .19 & $\begin{array}{c}\text { Gruplar } \\
\text { Arası }\end{array}$ & 166.48 & 2 & \multirow[t]{2}{*}{83.24} & \multirow{4}{*}{2.83} & \multirow{4}{*}{.06} & \multirow{4}{*}{$\begin{array}{l}\text { ÇOK } \\
\text { YAKIN }\end{array}$} \\
\hline & $1-5$ & 30 & 18.17 & 5.22 & .95 & Grup İçi & 25526.50 & 867 & & & & \\
\hline & $6-58$ & 32 & 21.34 & 3.87 & .68 & Tonlam & 2569298 & 869 & \multirow[t]{2}{*}{29.44} & & & \\
\hline & Toplam & 870 & 19.41 & 5.44 & .18 & Toplam & 25092.98 & 809 & & & & \\
\hline \multirow{4}{*}{ YG } & Hiç & 808 & 13.95 & 3.83 & .13 & $\begin{array}{c}\text { Gruplar } \\
\text { Arası }\end{array}$ & 35.77 & 2 & \multirow[t]{2}{*}{17.89} & \multirow{4}{*}{1.23} & \multirow{4}{*}{.29} & \multirow{4}{*}{ YOK } \\
\hline & $1-5$ & 30 & 13.20 & 4.25 & .78 & Grup İçi & 12594.26 & 867 & & & & \\
\hline & 6-58 & 32 & 14.72 & 2.70 & .48 & & & & \multirow[t]{2}{*}{14.53} & & & \\
\hline & Toplam & 870 & 13.95 & 3.81 & .13 & Ioplam & 12630.03 & 869 & & & & \\
\hline \multirow{4}{*}{ UG } & Hiç & 808 & 22.32 & 4.39 & .15 & $\begin{array}{l}\text { Gruplar } \\
\text { Arası }\end{array}$ & .32 & 2 & .161 & \multirow{4}{*}{.008} & \multirow{4}{*}{.99} & \multirow{4}{*}{ YOK } \\
\hline & $1-5$ & 30 & 22.42 & 4.60 & .84 & Grup İçi & 16661.59 & 867 & & & & \\
\hline & $6-58$ & 32 & 22.34 & 4.05 & .72 & \multirow{2}{*}{ Toplam } & & 869 & \multirow[t]{2}{*}{19.22} & & & \\
\hline & Toplam & 870 & 22.33 & 4.38 & .15 & & 10031.92 & 809 & & & & \\
\hline
\end{tabular}

Tablo 2'den de görülebileceği gibi Tek Yönlü Anova analizlerine göre futbolcuların ulusal takımlarda oynama sayılarına göre antrenörleriyle ilgili hiçbir liderlik gücü algısında (ZG, ÖZG, YG ve UG) anlamlı bir farklılık bulunmamıştır ( $p>0.05$ ). Ancak, futbolcuların ulusal takımda oynama sayıları ile ÖZG arasında anlamlı farklılığa çok yakın olan bir değer bulunmuştur $[\mathrm{F}(867)=2.83, \mathrm{p}<0.06]$. Tukey Testi, $1-5$ arasında ulusal takımlarda oynayan futbolcuların $(\bar{X}=21.34), 6-58$ arasında oynayan futbolculara göre $(\bar{X}=19.41)$ antrenörlerinin ÖZG'nü daha yüksek algıladıklarını ortaya koymuştur. Bulgular, ulusal takımlarda oynama ile oynamama arasında anlamlı bir fark ortaya koymamasına karşın, ulusal takımlarda oynayanların oynamayanlara göre, ÖZG ortalaması daha yüksektir. Genel olarak ÖZG ortalamalarına bakıldığında (Tablo 2), ulusal takımlarda hiç oynamamadan $(\bar{X}=18.17)$ az sayıda oynamaya doğru (1-5 arası) ÖZG algısı artmakta ( $\bar{X}=21.34)$, ulusal takımlarda daha çok sayıda oynamaya doğru ilerlendiğinde ise (6-58) ÖZG algısı biraz aşağıya düşmektedir $(\bar{X}=19.41)$.

\section{TARTIŞMA VE SONUÇ}

Bulgulardan elde edilen sonuçlara göre futbolcuların ulusal takımlarda oynama sayılarına göre antrenörleriyle ilgili hiçbir liderlik gücü algısında (ZG, ÖZG, YG ve UG) anlamlı bir fark bulunmamıştır. Ancak, ulusal takımda oynama sayıları ile ÖZG arasında anlamlı farklıı̆a çok yakın olan bir değer bulunmuştur $[F(867)=2.83, p<0.06]$. Ulusal takımlarda 6-58 arasında oynayan futbolcuların, 1-5 arasında oynayan futbolculara göre, antrenörlerinin ÖZG'nü daha yüksek algıladıkları saptanmıştır. Sonuçlar, ulusal takımlarda oynama ile oynamama arasında anlamlı bir farkı ortaya koymamasına karşın, ulusal takımlarda oynayanların oynamayanlara göre, ÖZG algıları daha yüksektir. Genel olarak ÖZG ortalamalarına bakıldığında (Tablo 2), ulusal takımlarda hiç oynamamadan az sayıda oynamaya doğru (1-5 arası) ÖZG algısı artmakta, ulusal takımlarda daha çok sayıda oynamaya doğru ilerlendiğinde ise (6-58) ÖZG algısı biraz aşağıya düşmektedir. Bu bir anlamda, ulusal takımlarda bulunma sıklığı ile ÖZG algısı arasındaki ters $U$ ilişkisini (curvilinear) göstermektedir. 
Bulgulardan elde edilen sonuçlar, ÖZG'nün sabit kalmaktan çok dinamik bir yapı gösterdiğini ortaya koymaktadır. Bu araştırma sonuçları da; Chelladurai ve Carron (17) ve Leith'in (16) olgunlaşma ve profesyonelliğe doğru ÖZG'nün azalacağı ve UG artacağına (Tablo 1) ilişkin araştırma sonuçlarını destekleyici değildir, Konter (25), Terry (20) ve Chelladurai ve Carron'nın (22), araştırma sonuçlarını ise, ÖZG ile ilgili desteklerken, YG ve UG ile ilgili olarak desteklememektedir. Araştırma sonuçları ayrıca Reimer ve Toon (21), tarafından ileri sürülen daha elit olan sporcuların daha çok olumlu geri bildirime (UG) gereksinim duyacakları görüşüne de destek vermemektedir. Araştırmalar topluca değerlendirildiğinde, kesin sonuçlar çıkarmanın henüz güç olduğu söylenebilir.

Ulusal takımlarda yer almamadan, az sayıda yer almaya, oradan da çok sayıda yer almaya doğru olan ilerleme; performans gelişim düzeyleri olarak düşünülebilir. Bazı araştırmalar; performans düzeylerini, başarılı olan ve olmayan, kazanan ve kaybeden, üst sıralarda ve alt sıralarda olan sporcu ve takımlara dayanarak ele almıştır (24,29). Ulusal takımda hiç yer almama, az sayıda yer alma ve daha çok sayıda yer almaya performans düzeyleri olarak bakıldığında, araştırmadan elde edilen sonuçlar; Garland ve Barry (29), Robinson ve Carron'ın (23) otoriterliğin (YG) performansı engelleyeceği ve buna kaşıt olarak Serpa ve arkadaşlarının (24) 1988 hentbol dünya şampiyonasında birinci olan takımların sonuncu olan takımlara göre daha yüksek otokratik davranış (YG), daha az olumlu geri bildirim (UG), sosyal destek (ÖZG) ve demokratik davranış (UG) algıladıklarına ilişkin sonuçlarını destekleyici değildir.

Araştırma sonuçları, ÖZG algısının ulusal takımlarda oynamada önemli bir değişken olduğunu göstermektedir. Ulusal takımların, ÖZG ile ilgili olarak kendilerine özgü özelliklere sahip oldukları da düşünülebilir. Örneğin; vatanla, milletle, bayrakla, takımla psikolojik bir bağ kurma ve bütünleşme ÖZG algısı ile ilişkilendirilebilir. Bu bağlamda; ulusal takımlarda oynayan futbolcuların, oynamayanlara göre, daha yüksek ÖZG algısının olmasının birkaç nedeni olabilir. Birincisi; ÖZG algısı yüksek olanların performansları da daha yüksek olduğundan, ulusal futbol takımlarına seçilmeleri daha kolay olabilir. İkincisi; performansla doğrudan ilişkili olmaksızın, ÖZG yüksek olan futbolcuların ulusal takımlara daha çok seçildikleri ileri sürülebilir. Başka bir deyişle; ya futbolcu yüksek ÖZG algısı nedeniyle daha yüksek performans ortaya koyarak ulusal takımlara daha çok seçilme şansını yakalamakta ya da ulusal takımlarda seçici olan antrenörlerin, daha yüksek ÖZG algısına sahip olanları ulusal takımlara seçmeleri söz konusu olmaktadır. Yukarıda da belirtildiği gibi, ÖZG algısının başarıda ve daha yüksek performans ortaya koymada önemli olduğunu gösteren araştırmalar olduğu gibi, olmadığını gösteren araştırmalar da vardır. Bu konuda araştırma sonuçları karışıktır ve kesin sonuçlar ortaya koymaktan uzaktır.

Ulusla, bayrakla, formayla bütünleşme, ulusal takımlarda oynayan futbolcular için oldukça önemlidir. ÖZG algıları yüksek olan futbolcuların, ulusal takımlarla özdeşleşim kurmaları ve yüksek performans ortaya koymaları daha kolay olabilir. Tersi olarak, ÖZG algısı düşük olan futbolcuların ise, ulusal takımlarla özdeşleşim kurmaları güç olabilir. Belki de bu nedenle, bu futbolcuların performansları iyi olsa da, ulusal takımlara çağrılmayabilirler veya ulusal takımlarda sürekliliklerini koruyamayabilirler.

Değişik kişilik yapılarına sahip ve değişik dünya görüşü olan futbolcuların yüksek performans ortaya koymaları değişik ortamları gerektirebilir. Her futbolcu, gittiği her ortamda, aynı düzeyde başarıları elde edemeyebilir. Ülke, bölge, şehir ve takım değiştiren futbolcular, ÖZG problemi nedeniyle başarısız sonuçlarla da karşılaşabilir.

ÖZG algıları yeterince yüksek olmayan futbolcular, antrenörleriyle uyumlu bir iletişim yakalamada zorlanabilir ve bu nedenle de performans düşüşü yaşayabilir. Bu durum futbolcunun ulusal takımlara seçilme ve ulusal takımlarda varlığını sürdürmesinde problem olabilir.

Ulusal takımlarda oynama ve üst düzeyde futbol liglerinde oynamanın, gelişmiş fiziksel, teknik, taktik ve psikolojik becerilerle meydana geldiği bilinmektedir (30). Daha iyi performansa sahip olanların üst liglere ve ulusal takımlara kadar yükseleceğinin ileri sürülebileceği gibi, üst liglerde ve ulusal takımlarda yer alan futbolcuların daha iyi performans ortaya koyacakları da beklenen bir durumdur. Benzer şekilde, ulusal takımlarda oynamada istikrara sahip olanlarla olmayanların, başarı ve performans ölçütlerinde farklılaşacağı düşünülebilir $(31,32,33,34,35,36,37,38)$.

Futbolcuların liderlik gücü algıları, onların eğitim düzeylerinden farklı olarak, kişilik özellikleriyle de ilişkili olabilir. Örneğin; motivasyonel yönelimler (18, 39), yüksek bilişsel yapı ve düşünmeden hareket etme (19) gibi.

Bu konuya ilgi duyan araştırmacılar, ulusal takımlarda oynama sıklıklarıyla ilgili daha sağlıklı sonuçlara varabilmek için kişilik özellikleri, elde edilen başarılar ve değişik performans ölçütlerini de (örn; değişik yaş gruplarından oluşan ulusal takımlar gibi) dikkate alabilirler.

\section{KAYNAKLAR}

1. Chelladurai, P., "Leadership in sports: A review", International Journal of Sport Psychology, 21, 328-354, 1990.

2. Wann, D. L., Metcalf, L. A., Brewer, K. R. Whiteside, H. D., “ Development of the Power in Sport Questionnaires”, Journal of Sport Behavior, 23, 423-443, 2000.

3. French, J. Raven, B. H., "The bases of social power". In. D. Cartwright, (Ed.). Studies in social power (pp.150-167).Ann Arbor: Institute for Social Research, 1959.

4. Chelladurai, P., "Discrepancy between preference and perception of leadership behavior and satisfaction of athletes in varying sports", Journal of Sport Psychology, 6, 27-41, 1984. 
5. Kelman, H. C., "Compliance, identification, and internalization: Three process of attitude change", Journal of Conflict Revolution, 2 , 51-60, 1958.

6. Yukl, G. Falbe, C. M., "Importance of different power sources in downward and lateral relations", Journal of Applied Psychology, 76, 416-423, 1991.

7. Horne, T. Carron, A. V., "Compatibility in coach-athlete relationships", Journal of Sport Psychology, 7, 137-149, 1985.

8. Riemer, H. A. ve Chelladurai, P., "Leadership and satisfaction in athletics", Journal of Sport and Exercise Psychology, 17, 276293, 1995.

9. Summers, R. J. Russel, J., "Association between athletes' perception of their abilities on the influence of coach technicalinstruction", Journal of Sport Behavior, 14(1), 30-40, 1991.

10. Laughlin, N. Laughlin, S., "The relationship between the similarity in perceptions of teacher/coach leader behavior and evolution of their effectiveness", International Journal of Sport Psychology, 22, 396-410, 1994.

11. Maby, R. K., "The relationship between perceived coaching behaviors and group cohesion in professional football", Nova Southeasthern University, Dissertation Abstracts International Section B, The Sciences and Engineering, 57(9-B), 5902, 1997.

12. Konter, E., "Profesyonel futbolcuların yaş gruplarına göre psikolojik becerilerinin araştırılması", Gazi Beden Eğitimi ve Spor Bilimleri Dergisi, X, I, 17-24, 2005.

13. Garland, D. J. Barry, J. R., "The effects of personality and perceived leader behavior on performance in collegiate football", Psychological Record, 38, 237-247, 1988.

14. Gordon, S., "Decision styles and coaching effectiveness in university soccer", Canadian Journal of Sport Science, 13(1), 36-55, 1998.

15. Prapavessis, H. Gordon, S., Coach/player relationships in tennis, Canadian, 1991.

16. Leith, L. M., The Psychology of Coaching Team Sports, A Self-Help Guide, Toronto. Sport Books Publisher, 2003.

17. Chelladurai, P., Carron, A. V., Leadership, Ottawa: Sociology of Sport Monograph Series. Canadian Association for Health, Physical Education and Recreation, 1978/

18. Erle, F. J., "Leadership in competitive and recreational sport", Unpublished mater's thesis. University of Western Ontario, London, Canada, 1981

19. Chelladurai, P., Carron, A. V., "Task characteristics and individual differences, and their relationship to preferred leadership in sports", In. G. C. Roberts and D. M. Landers (Eds.). Psychology of Motor Behavior and Sport. Champaign.IL : Human Kinetics, p.87, 1981.

20. Terry, P. C., "The coaching preferences of elite athletes competing at Universiade'83", Canadian Journal of Applied Sport Sciences, 9, 201-208, 1984.

21. Reimer, H. A. Toon, K., Leadership and satisfaction in tennis: Examination of congruencies, gender and ability. Research Quarterly for Exercise and Sport, 72, 243-256, 2001.

22. Chelladurai, P. Carron, A. V., "Athletic maturity and preferred leadership", Journal of Sport Psychology, 5, 371-380, 1983.

23. Robinson, T. T. Carron, A. V., "Personal and situational factors associated with dropping out versus maintaining participation in competitive sport", Journal of Sport Psychology, 4, 364-378, 1982.

24. Serpa, S. Pataco, V. Santos, F., "Leadership patterns in handball international competition", International Journal of Sport Psychology, 22, 78-89, 1991.

25. Konter, E., "Towards adaptation of self and other versions of the power in soccer questionnaire for Turkey", $4^{\text {th }}$. International Scientific Conference of Soccer and Tennis. 15 $5^{\text {th }}$ May, National Sports Academy, Sofia, Bulgaria, 2007.

26. Konter, E. Doğanay. A., "Futbolda amatör ve profesyonel olmaya göre bazı psikolojik becerilerin analizi.", Spor Hekimliği Dergisi, 37, 2, 2, 2002.

27. Konter, E., "Profesyonel Futbolcuların Bazı Değişkenlerre Göre Psikolojik Becerilerinin Araştırılması", Çukurova Üniversitesi, Sosyal Bilimler Enstitüsü Doktora Tezi Adana, 2002.

28. Reynolds, C. R. Livingston, R. B., Wilson, V., Measurement and Assessment in Education, Boston: Pearson Education Inc, 2006.

29. Garland, D. J. Barry, J. R., "Personality and leader behaviors in collegiate football: A multidimensional approach to performance", Journal of Research in Personality, 24(3), 355-370, 1990.

30. Goldberg, A. S., Sports Slump Busting, Human Kinetics, Illinois, 1998.

31. Kreiner-Phillips. K., Orlick. T., "Winning after winning: The psychology of ongoing excellence", The Sport Psychologist,7, 31-48, 1993.

32. McCaffrey. N., Orlick, T., "Mental factors related to excellence among top professional golfers", International Journal of Sport Psychology, 20, 256-278, 1989.

33. Nideffer, N. Segal, M. Lowry, M. Bond, J., "Identifying and developing world-class performers", In. The Practice of Sport Psychology. Tenenbaum, G. (Ed.). Fitness Information Technology Inc., West Virginia, 129-144, 2001.

34. Orlick, T. Partington, J., "The sport psychology analysis of critical components as viewed by Canadian olympic athletes", The Sport Psychologist, 1, 4-17, 1987.

35. Orlick, T., In Persuit of Excellence. Leisure Press, Champaign, Illinois, 1990.

36. Orlick. T., McCaffery. N., "Mental training with children for sport and life", The Sport Psychologist, 5, 322-334, 1991.

37. Partington, J. Orlick, T., "The sport psychology consultant olympic coaches' views", The Sport Psychologist, 1, 95-102, 1987.

38. Williams, J. M., Psychological Characteristics of Peak Performance. In. Applied Sport Psychology, Personal Growth to Peak Performance, Williams. J. M. (Ed.). Mayfield Publishing Company, California, 123-132, 1986.

39. Vallerand, R. J. Ratelle, C. F., "Intrinsic and extrinsic motivation: A hierarchical model”, In. E.L. Deci, R. M. Ryan (Eds.). Handbook of Self-Determination Research (pp. 37-63). Rochester, NY: University of Rochester Pres, 2002. 